\title{
Interaction between major dietary patterns and cardiorespiratory fitness on metabolic syndrome in Iranian adults: a cross- sectional study
}

Hossein Shahinfar ${ }^{1}$, Mahtab Ghanbari ${ }^{1}$, Yahya Jalilpiran ${ }^{2}$, Nastaran Payande ${ }^{1}$, Mahshid Shahavandi ${ }^{1}$, Nadia Babaei ${ }^{1}$, Kurosh Djafarian ${ }^{2}$, Cain C. C. Clark ${ }^{3}$ and Sakineh Shab-Bidar ${ }^{1^{*}}$

\begin{abstract}
Background: Several researches have been conducted on the associations between diet and cardiorespiratory fitness (CRF) and major cardiovascular risk factors. However, there is no report about the interaction between major dietary patterns and CRF on metabolic syndrome (MetS) and its components. To investigate the combined association of major dietary patterns and CRF on MetS and its components.

Methods: This cross-sectional study was conducted on 270 apparently healthy adults living in Tehran, Iran. Dietary intake was evaluated using a validated food frequency questionnaire (FFQ). CRF was assessed using a graded exercise treadmill test. Socio-economic status, anthropometric measures, biochemical parameters, and blood pressure were evaluated according to standard methods. Major dietary patterns were identified by factor analysis.

Results: Three major identified dietary patterns were (healthy, mixed, and western). Significant positive association was found between mixed dietary pattern and metabolic syndrome $(\mathrm{OR}=2.68,95 \% \mathrm{Cl}(1.92,7.78), P=0.04)$. There were not relations between tertiles of identified dietary patterns and remained outcomes. Those who had higher adherence to mixed pattern with also higher CRF showed a significant decrease for diastolic blood pressure $(P<$ 0.01). Also we found that there was no significant interaction between any of dietary patterns and CRF on odds of MetS.

Conclusions: Overall, adherence to mixed dietary pattern in this population was associated with increasing odds of MetS. However, nor CRF neither the combination of dietary patterns and CRF was related to the odds of MetS among Iranian adults. More studies are needed to clarify these associations and to consider interpersonal determinants.
\end{abstract}

Keywords: Dietary pattern, Cardiorespiratory fitness, Metabolic syndrome, VO2max

\footnotetext{
* Correspondence: s.shabbidar@gmail.com

${ }^{1}$ Department of Community Nutrition, School of Nutritional Sciences and Dietetics, Tehran University of Medical Sciences (TUMS), No 44, Hojjat-dost Alley, Naderi St., Keshavarz Blvd, Tehran, Iran

Full list of author information is available at the end of the article
}

C C The Author(s). 2021 Open Access This article is licensed under a Creative Commons Attribution 4.0 International License, which permits use, sharing, adaptation, distribution and reproduction in any medium or format, as long as you give appropriate credit to the original author(s) and the source, provide a link to the Creative Commons licence, and indicate if changes were made. The images or other third party material in this article are included in the article's Creative Commons licence, unless indicated otherwise in a credit line to the material. If material is not included in the article's Creative Commons licence and your intended use is not permitted by statutory regulation or exceeds the permitted use, you will need to obtain permission directly from the copyright holder. To view a copy of this licence, visit http://creativecommons.org/licenses/by/4.0/ The Creative Commons Public Domain Dedication waiver (http://creativecommons.org/publicdomain/zero/1.0/) applies to the data made available in this article, unless otherwise stated in a credit line to the data. 


\section{Introduction}

Metabolic syndrome (Mets) is a cluster of conditions that occur together, including excess fat accumulation around the waist, impaired metabolism of glucose due to insulin resistance, dyslipidemia such as increased blood triglycerides (TG), decreased high-density lipoprotein cholesterol (HDL-C) [1, 2]. The prevalence of metabolic syndrome components varies in different populations due to their genetic and lifestyle differences [3], But it is important to note that metabolic syndrome can predispose individuals to type II diabetes and cardiovascular disease [4, 5]. The results of several studies indicated that in addition to obesity, low cardiorespiratory fitness (CRF) is also one of the risk factors associated with metabolic syndrome. Interestingly, these studies showed that increasing amounts of physical activity and higher CRF in people contribute to their metabolic health even between obese individuals [610]. Cardiorespiratory fitness is also identified as a key predictor of premature death and cardiovascular disease [11-13]. CRF is defined as maximum capacity of the cardiovascular and respiratory system to supply oxygen to the skeletal muscles during exercise [5]. According to studies, CRF is positively associated with higher physical activity, lower BMI, and waist circumference in adults [14]. Lee et al., in a prospective longitudinal study of 3148 healthy adults, ages 18 or older, indicated that maintaining or improving fitness can reduce the risk of metabolic syndrome [15]. Besides, it seems that diet can be another important key to higher CRF and lower risk of Mets [14, 16]. According to previous evidence, CRF are positively associated with regular consumption of fruits, vegetables, bread and dairy products $[16,17]$, but the current approach of nutritional epidemiology is to research the effects of dietary patterns instead of food groups on CRF with different disease such as metabolic syndrome $[18,19]$. The results of a study on cardiorespiratory fitness and healthy dietary pattern showed that fitter teenagers have healthier dietary patterns than less fitter teenagers [17]. Also, The results of a clinical trial by Neuhouser et al. conducted on 48,835 postmenopausal women showed that the low-fat dietary pattern intervention for 1 year can reduce the risk of metabolic syndrome in postmenopausal women about $17 \%$ compared to postmenopausal women with usual dietary pattern [20]. Despite the studies mentioned, limited data are available on the study of CRF-related dietary patterns in the Middle East [21]. Only limited studies have examined the interaction of various factors with metabolic syndrome and other diseases [22-25]. Also based on our search no available study has evaluated the interaction between dietary patterns and cardiorespiratory fitness on metabolic syndrome. In this study, the interactions between major dietary patterns and cardiorespiratory fitness on metabolic syndrome in Iranian adults were investigated.

\section{Methods}

\section{Study design}

In this cross-sectional study, 270 apparently healthy adults, including 118 men, and 152 women enrolled. Participants were recruited by using convenience sampling method. Based on previously calculated correlation coefficient between dietary pattern and cardiorespiratory fitness [26]. our target number of participants was 256 (( $\left.\left.Z_{1-\frac{\alpha}{2}}+Z_{1-\beta} \times \sqrt{1-r^{2}} / \mathrm{r}\right)=256\right)$. However, in order to replace patients who were excluded due to under- or overreported food intakes, we continued sampling until enrolling 270 individuals.

The research criteria included an age range of 18-45, participants who apparently healthy, having desire to take part in the study, subjects who reside in Tehran. We excluded those who have extreme values of dietary intake (less than $800 \mathrm{kcal} / \mathrm{d}$ or more than $4200 \mathrm{kcal} / \mathrm{d}$, respectively), suffering from kidney, liver, and lung diseases and other conditions affecting the body composition status or infectious and active inflammatory diseases, pregnancy, lactation, routine supplement or drug use, such as weight loss, hormonal, sedative drugs, thermogenic supplements like caffeine and green tea, conjugated linoleic acid (CLA), etc. This study was conducted according to the guidelines laid down in the Declaration of Helsinki. All necessary explanations about the project were given to the participants. All procedures were in accord with the ethical standards of the Tehran University of Medical Sciences (Ethic Number: IR.TUMS.VCR.REC.1396.4085), who approved the protocol and informed consent form. All participants signed a written informed consent prior to the start of the study.

\section{Assessment of other variables}

Participants completed a questionnaire designed to assess the participants' demographic including age, gender (male/female), marital status (single/married), smoking (non-smoker/former smoker/current smoker), diabetes (yes/no), cardiovascular disease (yes/no) and menopause status (yes/no). Physical activity was assessed using the international physical activity questionnaire (IPAQ) [27]. Subjects were grouped into three categories including very low (<600 MET-minute/week), low (600-3000 MET-minute/week), moderate and high (>3000 METminute/week) calculated based on Metabolic Equivalents (METs) [28].

\section{Dietary intakes}

The dietary intake of participants was assessed by a valid and reliable semi-quantitative Food Frequency Questionnaire (FFQ), which contained 168 food items [29]. FFQ was administered by trained dietitians via face-to-face 
interviews, asking participants to report their frequency of consumption of each food item, during the past year on a daily, weekly, or monthly basis. To convert the portion sizes of the consumed foods to grams, household measures were used. Mean energy and nutrient intakes from the FFQs were calculated using a modified version of NUTRITIONIST IV software for Iranian foods (version 7.0; N-Squared Computing, Salem, OR, USA).

\section{Anthropometric measures}

Body weight was determined using a standard body weight scale (seca 707; Seca GmbH \& Co. KG., Hamburg, Germany). Height was measured with a tape measure mounted on the wall. Participant's height was measured without shoes by a Stadiometer (Seca, Germany). We measured waist circumference (WC) based on the middle of bottom ribs and pelvic bones after a normal exhale using an inelastic tape. To calculate waist-hip ratio (WHR), WC in centimeter divided by hip circumference in centimeter. Body mass index (BMI) calculated as weight in kilogram divided by height in meters squared. Body composition was measured using body composition analyzer (InBody 720, Biospace, Tokyo, Japan). For this analysis, all patients were asked to follow these conditions before measurement: no food ingestion for at least $4 \mathrm{~h}$, minimal intake of $2 \mathrm{~L}$ of water the day before, no physical activity for at least $8 \mathrm{~h}$, no coffee or alcoholic beverage consumption during at least $12 \mathrm{~h}$, and no diuretic use for at least $24 \mathrm{~h}$. Patients were required to empty their bladder immediately before the body composition test [30]. To assess blood pressure, first we asked participants to sit for $10 \mathrm{~min}$. Blood pressure was then measured using a standard mercury sphygmomanometer, twice with a $5 \mathrm{~min}$ interval, while participants were sitting. The mean of the two measurements was recorded as the participant's blood pressure.

\section{Laboratory investigations}

All participants donated $10 \mathrm{ml}$ of blood between the hours of $7-10 \mathrm{am}$, in a fasted status. Following this, blood samples were collected in acid-washed test tubes without anticoagulant. Then, after being stored at room temperature for $30 \mathrm{~min}$ and clot formation, blood samples were centrifuged at $1500 \mathrm{~g}$ for $20 \mathrm{~min}$. Serums were stored in $-80^{\circ} \mathrm{C}$ until future testing. Fasting blood sugar (FBS) was assayed by the enzymatic (glucose oxidase) colorimetric method using a commercial kit (Pars Azmun, Tehran, Iran). Serum total cholesterol (TC) and high-density lipoprotein cholesterol (HDL-C) were measured using a cholesterol oxidase phenol aminoantipyrine method, and triglyceride (TG) was measured using a glycerol-3 phosphate oxidase phenol aminoantipyrine enzymatic method. Serum low-density lipoprotein cholesterol (LDL-C) was calculated using the Fried Ewald formula.

\section{Definition of terms}

MetS was defined according to the National Cholesterol Education Program (NCEP) Adult Treatment Panel-III (ATP III) classification as three or more of WC $>102$ $\mathrm{cm}$ in males and $\mathrm{WC}>88 \mathrm{~cm}$ in females, fasting plasma glucose $\geq 110 \mathrm{mg} / \mathrm{dl}$ in both gender, or a known diagnosis diabetes, fasting serum triglyceride $\geq 150 \mathrm{mg} / \mathrm{dl}$ in both gender, fasting high-density lipoprotein (HDL) cholesterol $<40 \mathrm{mg} / \mathrm{dl}$ in males and $\mathrm{HDL}<50 \mathrm{mg} / \mathrm{dl}$ in females, or blood pressure $\geq 130 / 85 \mathrm{mmHg}$ in both gender [31].

\section{Cardiorespiratory fitness testing}

To assess CRF, the maximum rate of oxygen consumed (VO2 max) by the treadmill, and the respiratory gas analyzer (Cortex Metabolizer 3B) was measured. Accordingly, the participants warmed up for $5 \mathrm{~min}$ on the treadmill at a speed of $5 \mathrm{~km} / \mathrm{h}$, and then the Bruce test was used to determine the VO2max [32]. After completing the Bruce test, the participants walked at a speed of $4 \mathrm{~km} / \mathrm{h}$ in order to cool down for $3 \mathrm{~min}$ and perform 10 to $5 \mathrm{~min}$ of stretching. The conditions for the end of the test were: the patient's heart rate reaches more than $90 \%$ of the maximum heart rate, the ratio of respiratory rate of up to 1.1, and having the plateau rate of oxygen intake, despite the increase in exercise intensity.

\section{Dietary patterns}

Foods and beverages from the FFQ were categorized into 17 food groups based on the similarity of nutrients. Factor loadings for each of the 25 food groups were estimated using principle component analysis (PCA) method. Orthogonal transformation was used to keep identified factors uncorrelated and to improve the interpretation. Eigenvalues, the scree plot test, and interpretability were evaluated to retain factors $(>1.5)$ for further analysis. An absolute factor loading $\geq 0.3$ was used to define a subset of at least 6 food groups in each factor. The identified factors were labeled based on our interpretation of the data and based on previous studies that found similar dietary patterns in adults [33-35]. Factor scores for each pattern were obtained by summing intakes of food groups weighted by their factor loadings [36]. Each participant received a factor score for each identified pattern. Participants were categorized based on tertiles of dietary pattern scores.

\section{Statistical analysis}

All statistical analyses were performed using the Statistical Package for the Social Sciences (SPSS version 25; SPSS Inc.). We considered $p<0.05$ as significance level. 
Participants were divided based on the tertiles of major dietary patterns and CRF. To compare general characteristics among tertiles, we used one-way ANOVA and chi-square tests for quantitative (height, age, fat free mas, fat mass, weight, waist circumference, waist to hip ratio, and body mass index) and qualitative variables (sex, marital status, smoking, physical activity, history of diabetes and cardiovascular disease and menopause status), respectively. Multivariate adjusted means test was performed to evaluate the association between major dietary patterns, CRF and MetS components and each of its components after adjusting for potential confounders. Two-way ANOVA was used to investigate the combined association of major dietary patterns and CRF on MetS components. Participants were categorized as dichotomously according to ATP III guideline values and first teriles were regarded as the reference group. Multivariate adjusted odds ratios test was done for indicating the interaction between CRF and dietary pattern with MetS.

\section{Results}

Mean age of participants was $36.71 \pm 13.18$. The mean BMI was $25.61 \pm 4.67$ for them. The prevalence of abdominal obesity among men and women was 23.7 and $40.8 \%$ respectively. A total of 270 participants (117 men and 153 women) were included in this study. General characteristics of study participants by tertiles of CRF are shown in Table 1 . There were also no statistical differences in distribution of smoking, and history of CVD across tertiles of CRF. General characteristics of participants across the tertiles of three major dietary patterns are indicated in Table 2. Participants in the highest

Table 1 General characteristics of study participants by tertiles of CRF

\begin{tabular}{|c|c|c|c|c|c|}
\hline & \multirow{2}{*}{$\begin{array}{l}\text { All }=270 \\
\text { Mean } \pm \text { SD } \\
\text { or\% }\end{array}$} & \multicolumn{3}{|c|}{ Tertiles of CRF } & \multirow[t]{2}{*}{$P_{\text {value }}$} \\
\hline & & $\overline{\mathrm{T} 1}$ & $\mathrm{~T} 2$ & T3 & \\
\hline $\mathrm{n}$ & 270 & 90 & 88 & 92 & \\
\hline Height $(\mathrm{cm})$ & $168 \pm 9.96$ & $163 \pm 9.57$ & $166 \pm 49$ & $174 \pm 7.93$ & $<0.001$ \\
\hline Age (year) & $36.7 \pm 13.18$ & $42.8 \pm 13.78$ & $35.2 \pm 12.36$ & $32.1 \pm 11.02$ & $<0.001$ \\
\hline FFM (kg) & $50.1 \pm 12.65$ & $46.6 \pm 11.40$ & $47.2 \pm 12.68$ & $56.3 \pm 11.49$ & $<0.001$ \\
\hline FM (kg) & $22.4 \pm 9.39$ & $27.9 \pm 10.23$ & $23.2 \pm 7.27$ & $16.3 \pm 6.34$ & $<0.001$ \\
\hline Weight (kg) & $72.7 \pm 16.06$ & $74.5 \pm 17.82$ & $71.0 \pm 16.34$ & $72.6 \pm 13.82$ & 0.34 \\
\hline \multicolumn{6}{|l|}{ WC (cm) } \\
\hline Men & $93.9 \pm 12.4$ & $105 \pm 12.7$ & $100 \pm 10.8$ & $88.4 \pm 9.74$ & $<0.001$ \\
\hline Women & $86.3 \pm 11.7$ & $90.9 \pm 12.3$ & $83.3 \pm 9.23$ & $78.4 \pm 8.21$ & $<0.001$ \\
\hline WHR & $0.90 \pm 0.06$ & $0.92 \pm 0.05$ & $0.91 \pm 0.06$ & $0.87 \pm 0.06$ & $<0.001$ \\
\hline BMI (kg/m2) & $25.6 \pm 4.67$ & $27.6 \pm 5.36$ & $25.3 \pm 4.12$ & $23.8 \pm 3.62$ & $<0.001$ \\
\hline Sex, male, n(\%) & $117(43.5 \%)$ & $16(5.9 \%)$ & $32(11.9 \%)$ & $69(25.7)$ & $<0.001$ \\
\hline Marital status,n(\%) & & & & & $<0.001$ \\
\hline Single & $115(43.3)$ & $23(8.6)$ & $36(13.5)$ & $57(21.3)$ & \\
\hline Married & $152(56.7)$ & $66(24.6)$ & $51(19.0)$ & $35(13.0)$ & \\
\hline Smoking, n(\%) & & & & & 0.33 \\
\hline Non-smoker & 233(86.9) & $83(31.0)$ & $75(28.0)$ & $75(28.0)$ & \\
\hline Former and current smoker & $35(13.1)$ & $6(2.20)$ & $12(4.50)$ & $17(6.30)$ & \\
\hline Physical activity, n(\%) & & & & & $<0.001$ \\
\hline Low & 103(38.4) & $43(16.0)$ & $39(14.6)$ & $21(7.80)$ & \\
\hline Medium & $110(41.0)$ & $37(13.8)$ & $34(12.7)$ & $39(14.6)$ & \\
\hline high & $55(20.5)$ & $9(3.40)$ & 14(5.20) & $32(11.9)$ & \\
\hline Diabetes, yes, n(\%) & $9(3.40)$ & $7(2.60)$ & $2(0.70)$ & $0(0.0)$ & 0.01 \\
\hline CVD, yes, n(\%) & $5(1.90)$ & $3(1.10)$ & $1(0.40)$ & $1(0.40)$ & 0.43 \\
\hline $\begin{array}{l}\text { Menopause status, yes, } \\
\text { n (\%) }\end{array}$ & $36(13.5)$ & $34(12.7)$ & $2(0.70)$ & $0(0.0)$ & $<0.001$ \\
\hline
\end{tabular}

$P$ value less than 0.05 was considered significant

Values are based on average \pm standard deviation or reported number (percentage)

One-way anova for quantitative data and $\mathrm{Chi}-2$ test for qualitative data have been used

BMI Body Mass Index, WC Waist Circumference, FFM fat free mass, FM fat mass, WHR waist to hip ratio, CRF cardiorespiratory fitness 


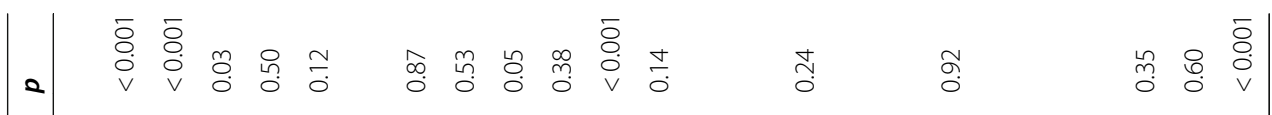

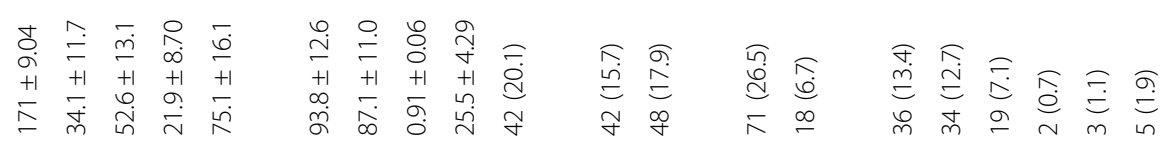

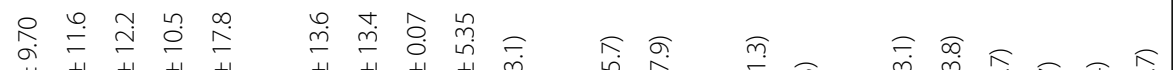

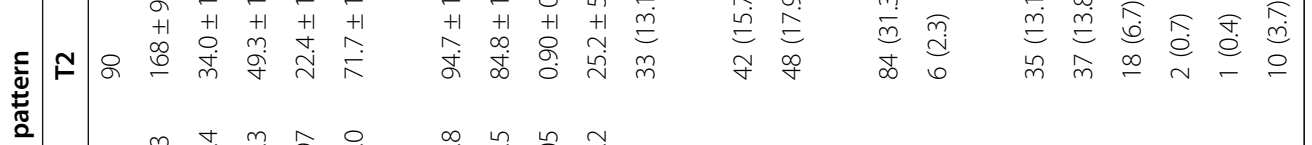

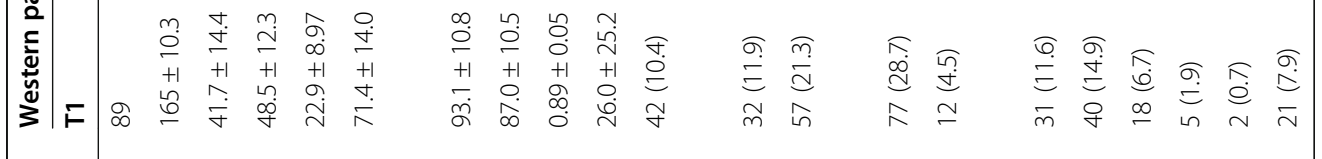

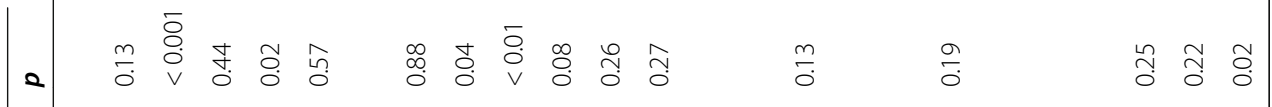

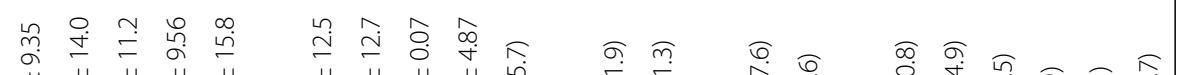

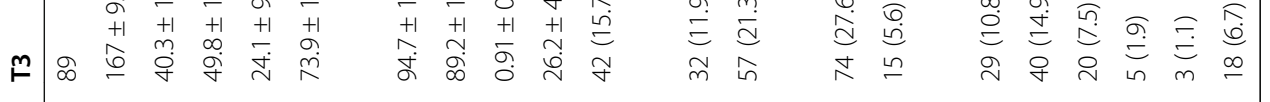

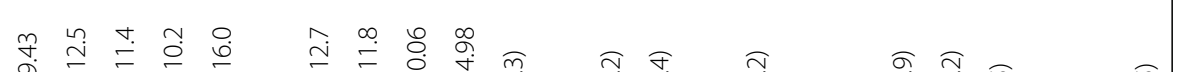

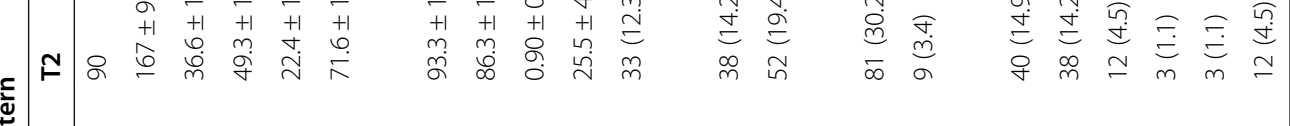

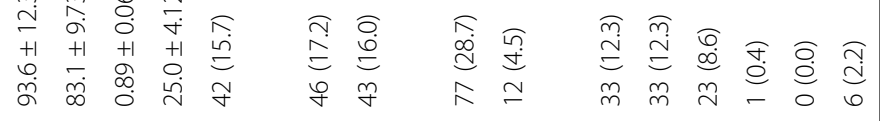

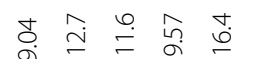

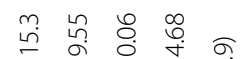

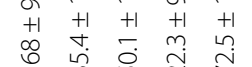

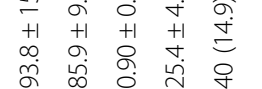

ชิ

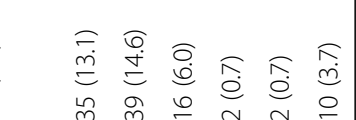

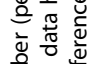

है 
Table 3 Food groups and their loading factors for three identified dietary patterns

\begin{tabular}{|c|c|c|c|c|}
\hline & \multirow[t]{2}{*}{ Group details } & \multicolumn{3}{|c|}{ Dietary Patterns } \\
\hline & & $\begin{array}{l}\text { Healthy } \\
\text { pattern }\end{array}$ & $\begin{array}{l}\text { Mixed } \\
\text { pattern }\end{array}$ & $\begin{array}{l}\text { Western } \\
\text { pattern }\end{array}$ \\
\hline Organ meats & Heart, kidney, liver, tongue, brain, offal, rennet & & & \\
\hline Salt & Salt & & & \\
\hline Potato & Potato & & & \\
\hline $\begin{array}{l}\text { Hydrogenated } \\
\text { fats }\end{array}$ & Hydrogenated vegetable oils, solid fats (animal origin), animal butter, margarine & & & \\
\hline Poultry & Chicken & 0.727 & & \\
\hline Egg & Egg & 0.648 & & \\
\hline Legumes & Lentils, split pea, beans, chick pea, fava bean, soy, others & 0.623 & & \\
\hline $\begin{array}{l}\text { Fruits and } \\
\text { Juices }\end{array}$ & $\begin{array}{l}\text { Melon, watermelon, honeydew melon, plums, prunes, apples, cherries, sour cherries, peaches, } \\
\text { nectarine, pear, fig, date, grapes, kiwi, pomegranate, strawberry, banana, persimmon, berry, } \\
\text { pineapple, oranges, dried fruits, all juices, others }\end{array}$ & 0.582 & & \\
\hline Fishes & All fish types & 0.581 & & \\
\hline Nuts & Almonds, peanut, walnut, pistachio, hazelnut, seeds, others & 0.485 & & \\
\hline $\begin{array}{l}\text { Olive and olive } \\
\text { oil }\end{array}$ & Olive and olive oil & 0.453 & & \\
\hline $\begin{array}{l}\text { Low fat dairy } \\
\text { product }\end{array}$ & Low-fat milk, skim milk, low-fat yogurt, cheese, Kashk, yogurt drink, others & 0.451 & & \\
\hline Mayonnaise & Mayonnaise & & 0.767 & \\
\hline Pickles & & & 0.718 & \\
\hline $\begin{array}{l}\text { High fat dairy } \\
\text { product }\end{array}$ & High-fat milk, high-fat yogurt, cream cheese, cream, dairy fat, ice cream, others & & 0.543 & \\
\hline $\begin{array}{l}\text { Non-refined } \\
\text { cereals }\end{array}$ & Dark breads (e.g., barbari, sangak, taftun), bran breads, others & & 0.468 & \\
\hline Vegetables & $\begin{array}{l}\text { Cauliflower, carrot, tomato and its products, spinach, lettuce, cucumber, eggplant, onion, } \\
\text { greens, green bean, green pea, squash, mushroom, pepper, corn, garlic, turnip, others }\end{array}$ & 0.538 & 0.467 & \\
\hline Vegetable oils & Vegetable oils (except for olive oils) & & 0.428 & \\
\hline Soft drinks & Soft drinks & & & 0.699 \\
\hline French fries & French fries & & & 0.621 \\
\hline Salty snacks & Corn puffs, crackers, potato chips, others & & & 0.547 \\
\hline $\begin{array}{l}\text { Sweets and } \\
\text { desserts }\end{array}$ & $\begin{array}{l}\text { Cookies, cakes, biscuits, muffins, pies, chocolates, honey, jam, sugar cubes, sugar, candies, } \\
\text { sweet tahini, others }\end{array}$ & & & 0.469 \\
\hline Refined cereals & Lavash bread, baguette bread, rice, pasta, others & & & 0.456 \\
\hline $\begin{array}{l}\text { Red and } \\
\text { processed } \\
\text { meats }\end{array}$ & Beef and veal, lamb, minced meat, sausage, deli meat, hamburger & & & 0.401 \\
\hline Tea and coffee & Tea and coffee & & & 0.313 \\
\hline
\end{tabular}

Factor loadings $<0.03$ for all three patterns were excluded

tertile of Healthy dietary pattern (HDP) had highest BMI $(p$-value $=0.01)$, WC $(p$-value $=0.01)$. Adherence to mixed dietary pattern showed a significant increase for FM $(p$-value $=0.02), \operatorname{WHR}(p$-value $<0.01)$. Participants in the highest tertile of Western dietary pattern (WDP) had the highest FFM ( $p$-value $=0.03)$. There were also no statistical differences in distribution of marital status, smoking and physical activity level across tertiles of all dietary patterns (Table 2). Three major dietary patterns were identified (Supplementary Fig. 1) by factor analysis which explained $34.77 \%$ of the total variance in dietary intakes amount. Table 3 shows food groups and their loading factors for three major identified dietary patterns. Positive loading demonstrated strong associations between the food groups and dietary patterns, while negative loading demonstrated negative associations (Table 3). Multivariate adjusted means for FBS, TG, WC, HDL, SBP, and DBP across tertiles of major dietary patterns are indicated in Table 4. The results showed that participants in the highest tertile of WDP had the highest TG $(p=0.03)$. A significant decrease was showed for WC across the tertiles of CRF ( $p$-value $<0.01)$. Also, 
Table 4 Multivariate adjusted means for FBS, TG, WC, HDL, SBP, and DBP across tertiles of major dietary patterns and CRF

\begin{tabular}{|c|c|c|c|c|c|c|}
\hline & \multicolumn{6}{|c|}{ Tertiles of major dietary patterns } \\
\hline & \multicolumn{6}{|c|}{ Healthy Dietary Pattern } \\
\hline & $\mathrm{T} 1$ & $\mathrm{~T} 2$ & T3 & $P^{*}$ & $P_{\text {Trend }}$ & $P \$$ \\
\hline FBS (mg/dl) & $98.5 \pm 12.0$ & $96.7 \pm 10.5$ & $99.9 \pm 28.6$ & 0.53 & 0.63 & 0.72 \\
\hline TG (mg/dl) & $117 \pm 65.5$ & $132 \pm 80.5$ & $109 \pm 59.8$ & 0.08 & 0.46 & 0.10 \\
\hline HDL (mg/dl) & $49.1 \pm 10.5$ & $50.8 \pm 11.7$ & $189 \pm 40.2$ & 0.47 & 0.98 & 0.50 \\
\hline SBP $(\mathrm{mmHg})$ & $106 \pm 26.9$ & $110 \pm 10.8$ & $116 \pm 14.5$ & $<0.01$ & $<0.001$ & 0.15 \\
\hline $\mathrm{DBP}(\mathrm{mmHg})$ & $69.9 \pm 11.7$ & $69.7 \pm 10.4$ & $72.2 \pm 9.75$ & 0.22 & 0.15 & 0.72 \\
\hline \multicolumn{7}{|l|}{ WC (cm) } \\
\hline Men & $93.3 \pm 11.4$ & $93.8 \pm 15.3$ & $94.4 \pm 10.4$ & 0.93 & 0.72 & 0.07 \\
\hline \multirow[t]{3}{*}{ Women } & $84.2 \pm 11.4$ & $85.9 \pm 9.55$ & $89.4 \pm 13.8$ & 0.08 & 0.02 & 0.08 \\
\hline & \multicolumn{6}{|c|}{ Mixed Dietary Pattern } \\
\hline & $\mathrm{T} 1$ & $\mathrm{~T} 2$ & T3 & $P$ & $\mathrm{P}_{\text {Trend }}$ & $P \$$ \\
\hline FBS (mg/dl) & $101 \pm 28.6$ & $97.98 \pm 10.29$ & $96.2 \pm 11.5$ & 0.23 & 0.09 & $<0.01$ \\
\hline TG (mg/dl) & $116 \pm 69.7$ & $124.90 \pm 72.44$ & $117 \pm 67.1$ & 0.70 & 0.92 & 0.81 \\
\hline HDL (mg/dl) & $49.5 \pm 9.81$ & $50.54 \pm 11.97$ & $49.1 \pm 10.2$ & 0.67 & 0.82 & 0.55 \\
\hline SBP (mmHg) & $109 \pm 18.6$ & $110.75 \pm 20.74$ & $114 \pm 17.8$ & 0.22 & 0.09 & 0.94 \\
\hline DBP (mmHg) & $69.7 \pm 8.31$ & $69.23 \pm 12.38$ & $72.9 \pm 10.7$ & 0.04 & 0.04 & 0.63 \\
\hline \multicolumn{7}{|l|}{$W C(\mathrm{~cm})$} \\
\hline Men & $93.6 \pm 12.3$ & $93.3 \pm 12.7$ & $94.7 \pm 12.5$ & 0.88 & 0.68 & 0.14 \\
\hline \multirow[t]{3}{*}{ Women } & $83.1 \pm 9.73$ & $86.3 \pm 11.8$ & $89.2 \pm 12.7$ & 0.04 & 0.01 & 0.61 \\
\hline & \multicolumn{6}{|c|}{ Western Dietary Pattern } \\
\hline & $\mathrm{T} 1$ & $\mathrm{~T} 2$ & T3 & $P$ & $\mathrm{P}_{\text {Trend }}$ & $P \$$ \\
\hline FBS (mg/dl) & $97.9 \pm 8.81$ & $97.2 \pm 12.6$ & $100 \pm 28.8$ & 0.56 & 0.46 & 0.80 \\
\hline TG (mg/dl) & $108 \pm 54.90$ & $129 \pm 75.1$ & $122 \pm 75.9$ & 0.10 & 0.17 & 0.03 \\
\hline HDL (mg/dl) & $49.5 \pm 9.84$ & $50.3 \pm 11.5$ & $49.3 \pm 10.7$ & 0.80 & 0.52 & 0.86 \\
\hline SBP $(\mathrm{mmHg})$ & $114 \pm 18.04$ & $110 \pm 19.7$ & $109 \pm 19.5$ & 0.24 & 0.13 & 0.25 \\
\hline $\mathrm{DBP}(\mathrm{mmHg})$ & $70.0 \pm 13.11$ & $70.2 \pm 8.81$ & $71.5 \pm 9.80$ & 0.59 & 0.35 & 0.17 \\
\hline \multicolumn{7}{|l|}{ WC (cm) } \\
\hline Men & $93.1 \pm 10.8$ & $94.7 \pm 13.6$ & $93.8 \pm 12.6$ & 0.87 & 0.83 & 0.61 \\
\hline \multirow[t]{3}{*}{ Women } & $87.0 \pm 10.5$ & $84.8 \pm 13.4$ & $87.1 \pm 11.0$ & 0.53 & 0.96 & 0.80 \\
\hline & \multicolumn{6}{|c|}{ Cardiorespiratory fitness (ml/kg/min) } \\
\hline & $\mathrm{T} 1$ & $\mathrm{~T} 2$ & T3 & $P$ & $\mathrm{P}_{\text {Trend }}$ & $P \$$ \\
\hline FBS (mg/dl) & $97.5 \pm 9.76$ & $100 \pm 27.5$ & $97.5 \pm 14.9$ & 0.58 & 0.98 & 0.59 \\
\hline TG (mg/dl) & $123 \pm 60.7$ & $125 \pm 80.2$ & $110 \pm 66.4$ & 0.27 & 0.20 & 0.61 \\
\hline HDL (mg/dl) & $49.8 \pm 9.16$ & $49.5 \pm 12.0$ & $49.9 \pm 10.7$ & 0.95 & 0.93 & 0.96 \\
\hline SBP $(\mathrm{mmHg})$ & $108 \pm 27.9$ & $111 \pm 13.76$ & $114 \pm 11.1$ & 0.12 & 0.04 & $<0.001$ \\
\hline DBP (mmHg) & $71.1 \pm 12.2$ & $70.2 \pm 11.7$ & $70.3 \pm 7.69$ & 0.81 & 0.59 & 0.62 \\
\hline \multicolumn{7}{|l|}{ WC (cm) } \\
\hline Men & $105 \pm 12.7$ & $100 \pm 10.8$ & $88.4 \pm 9.74$ & $<0.001$ & $<0.001$ & 0.52 \\
\hline Women & $90.9 \pm 12.3$ & $83.3 \pm 9.23$ & $78.4 \pm 8.21$ & $<0.001$ & $<0.001$ & 0.45 \\
\hline
\end{tabular}

Values are presented as mean $\pm S D$

Abbreviations: FBS Fasting Blood Sugar, TG Triglyceride, HDL High Density Lipoprotein, SBP Systolic Blood Pressure, DBP Diastolic Blood, WC Waist Circumference *obtained using one-way ANOVA test

\$ obtained using analysis of covariance (ANCOVA) test (adjusted for age, sex, marital status, physical activity, smoking, total energy, diabetes, cardiovascular disease history, menopause status, and body mass index 


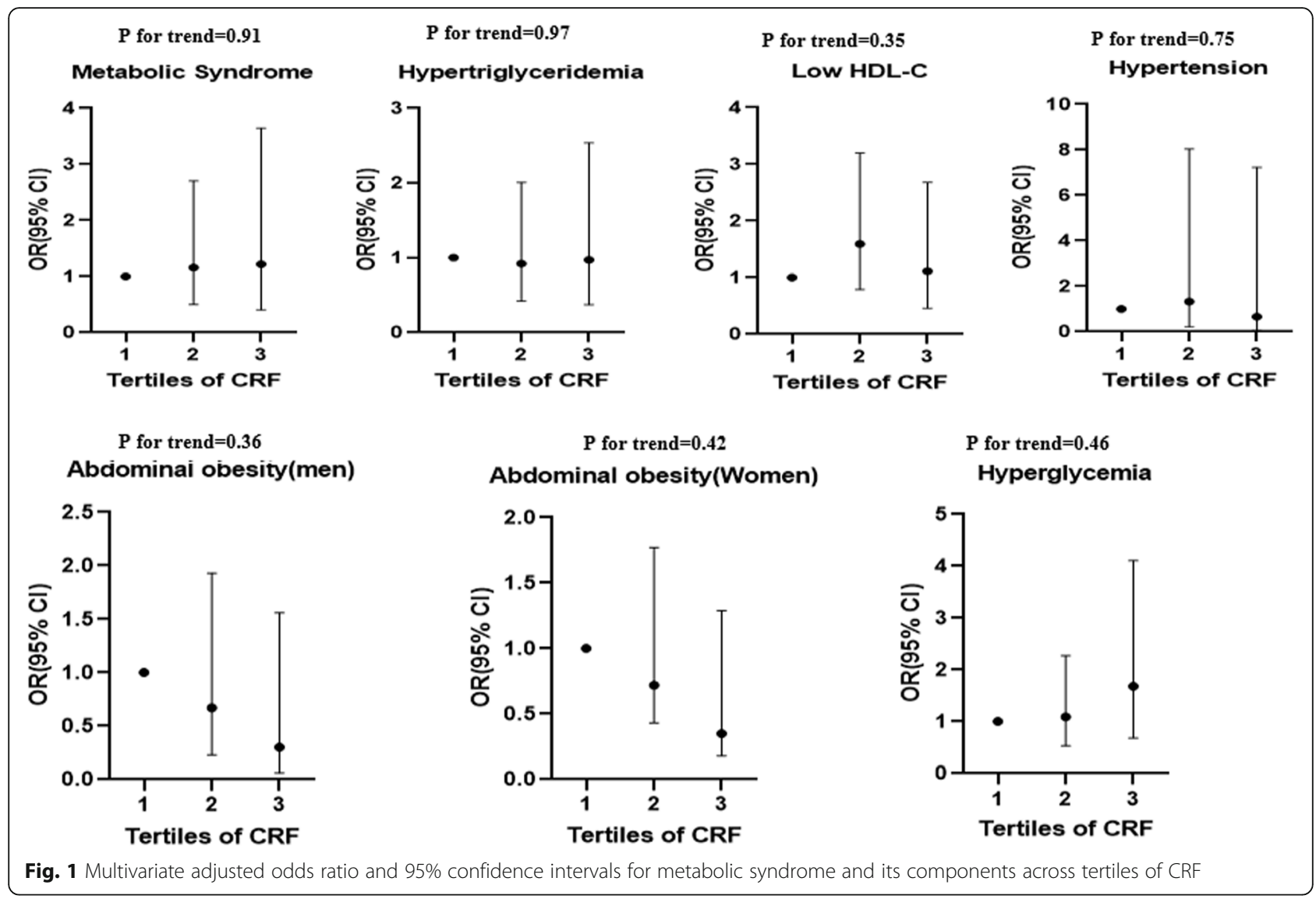

Participants in the highest tertile of CRF had the highest SBP ( $p$-value $<0.001)$, and participants in highest tertile of MDP had the lowest FBS $(<0.01)$. Figure 1 shows multivariate-adjusted odds ratios and $95 \%$ confidence intervals for metabolic syndrome and its components across tertiles of CRF. Multiple logistic regression models showed that there was no association between risk of metabolic syndrome and its components. Multivariate adjusted odds ratios and 95\% confidence intervals for metabolic syndrome and its components across tertiles of identified dietary patterns are summarized in Figs. 2, 3, and 4. After controlling for potential covariates our results indicated significant positive association (highest vs lowest tertile) between MDP and metabolic syndrome $(P=0.04, \quad \mathrm{OR}=2.68,95 \%$ CI $(1.92-7.78))$. There were not relations between tertiles of identified dietary patterns and remained outcomes. Multivariate adjusted odds ratios and 95\% confidence intervals for interaction between CRF and identified dietary patterns with metabolic syndrome are indicated in Table 5 . The results showed that there was no significant interaction between CRF and HDP $(p=0.69), \operatorname{MDP}(p=0.80)$, and WDP $(p=0.60)$ with odds of metabolic syndrome after adjustment for potential confounders. Multivariate adjusted means for interaction between CRF and dietary patterns with metabolic syndrome components are shown in Table 6. Adherence to WDP showed a significant decrease for HDL across tertiles of $\operatorname{CRF}(p$-value $=$ 0.03). Also, adherence to HDP indicated a significant increase for SBP across tertiles of CRF $(p=0.03)$. Moreover, adherence to MDP showed a significant decrease for WC $(p$-value $=0.05)$ and DBP $(p$-value $<0.01)$ across tertiles of CRF (Table 6).

\section{Discussion}

Previous researches have centralized mainly on the independent effects of dietary pattern and CRF on MetS risk. In this article, in addition to examining the independent effect of dietary pattern and CRF on MetS, we have evaluated the combined association between dietary pattern, CRF, and MetS. In this cross-sectional study, we identified three major dietary patterns including healthy, mixed, and western patterns. HDP and WDP had no statistically significant association with metabolic syndrome. However, there is a statistically significant between MDP and metabolic syndrome. We found having a higher score on the CRF compared with a lower score was associated with decreased odds of MetS, however, were not statistically significant. In addition, we found that there was no interaction of any dietary 


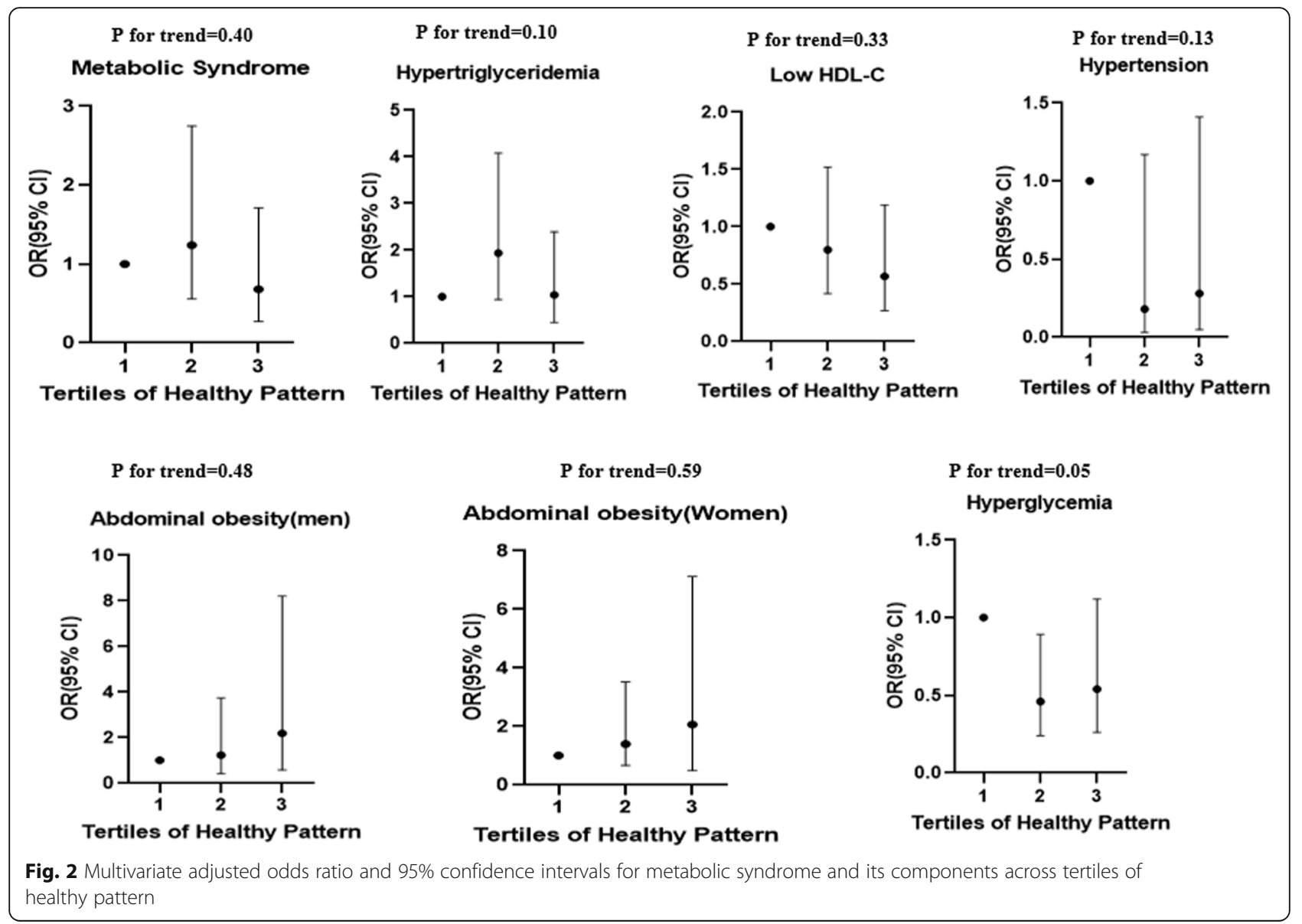

patterns (healthy, mixed, and western pattern) and CRF on odds of MetS. However, Adherence to WDP showed a significant decrease for HDL across tertiles of CRF. Adherence to HDP indicated a significant increase for SBP across tertiles of CRF and adherence to MDP showed a significant decrease for WC and DBP across tertiles of CRF.

To date, several epidemiological studies have been performed on the impact of dietary pattern on MetS. Evidence from a cross-sectional study of 4984 women aged 30-79 years indicated that HDP (high in green-yellow vegetables, healthy-protein foods, seaweeds, and bonefish) is associated with a decreased risk for MetS [37]. In another study by Esmaillzadeh et al., in 486 Tehrani female teachers the HDP (high in fruits, poultry, and vegetables) was associated with less prevalence of the MetS [34]. Williams et al., in a cross-sectional study of 802 UK-population aged 40-65 years reported that a HDP (high in fruits, raw and salad vegetables, fish, and low in fried foods) is associated with decreased central obesity and fasting glucose concentration [38]. In addition, a previous prospective study of 15,972 white and black men and women 45 to 64 years of age revealed adherence to prudent dietary pattern that described by intakes of cruciferous and carotenoid vegetables, fruit, fish, and poultry, was not correlated with an increase in the prevalence of MetS [39]. In the current study, it seems that a HDP (high in legumes, vegetables, poultry, fruits and fruits juices, nuts, fish, egg, low-fat dairy product, olive, and olive oil) is neither associated with a reduction in the prevalence of metabolic syndrome nor its components. In the present study, other factors such as weight control in people who have a HDP may affect the desired effects. For example, in our study, participants in the highest tertile of HDP had highest BMI, weight, and WC. Besides, participants in the highest tertile of HDP are older than those in the lowest tertile. The prevalence of metabolic syndrome increases with age, so this may be influential. Generally, although the HDP identified in our study is rich in foods that have the potential to reduce the risk of metabolic syndrome but it cannot be propounded exclusively a health-promoting diet. This pattern is more a reflection of the effort to choose healthy foods.

WDP that is determined by excessive consumption of fat, sweets, and refined grains showed inconsistent results with metabolic syndrome and its components [4042]. In research by Cho et al., the WDP (high in fast 


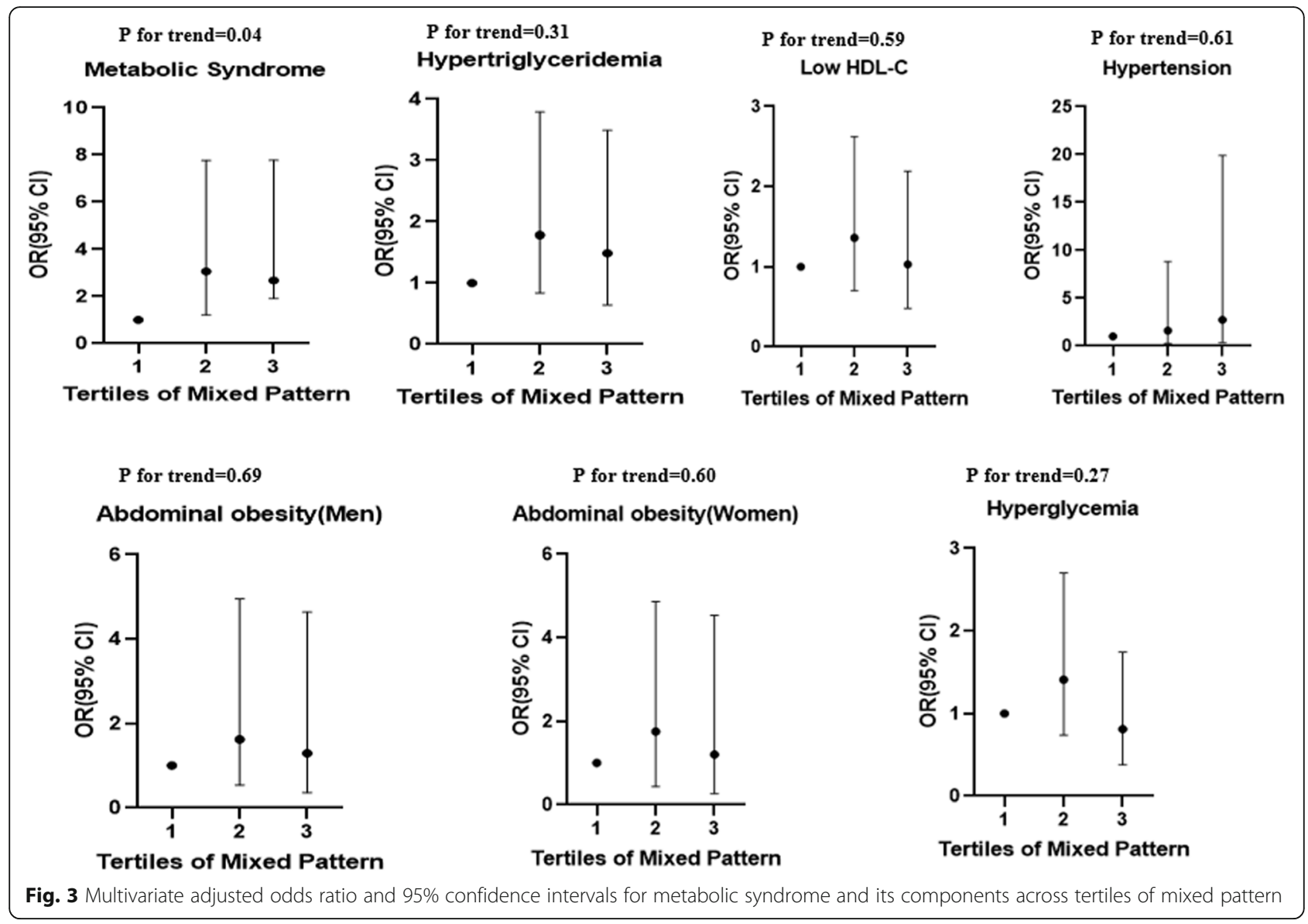

foods, animal fat-rich foods, fried foods, grilled meat and seafoods, and sweet foods) indicated no association with MetS [37]. However, WDP in 486 Tehrani female teachers in the study of Esmaillzadeh et al., was related to greater risks of MetS [34]. Adherence to a WDP that determined by high consumption of refined grains, processed meat, fried foods, and red meat, was correlated with an 18\% higher risk of occurrence MetS [43]. In our study, Dietary consumption of a WDP (including refined cereals, red or processed meat, soft drinks, sweets and desserts, tea and coffee, salty snacks, and french fries) was not correlated with an increased risk of metabolic syndrome and its components. Perhaps one of the reasons for this conclusion is the menopausal status in WDP tertiles. As state in results, Participants in the top tertile of WDP had less menopause status. Evidence from several studies suggested postmenopausal status is correlated with an increased risk of the metabolic syndrome independent of age $[44,45]$. In this regard reported the menopausal transition is linked with an increase in abdominal adiposity, independent of age and total body adiposity [46].

In relation to the MDP, which has a combination of healthy (non-refined cereals, vegetables, vegetable oils) and unhealthy (mayonnaise, high-fat dairy product) foods in present study is almost identical to the pattern described in Esmaillzadeh and colleagues study as the traditional food pattern [34]. It has been suggested that healthy combinations of this pattern can have a protective effect on the syndrome, while unhealthy foods can have a negative effect on the prevalence of the syndrome. As well as, the synergistic effect of other food compounds on HDP may be a factor in reducing the risk of metabolic syndrome [34]. The result of our analysis showed Dietary consumption of a MDP (high consumption of non-refined cereals, vegetable oils, mayonnaise, high-fat dairy product, and pickles) was not associated with odds of metabolic syndrome or its components. Anthropometric characteristics and also menopause status may influence the relationship between the MDP and the metabolic syndrome. In this pattern subjects in the highest tertile of MDP had highest FM, WC, WHR, and menopause status. Several studies have reported an opposite association between metabolic syndrome and the amount of body fat [47-49] and menopausal status $[50,51]$.

Our results indicated that having a higher score on the CRF compared with a lower score was associated with 


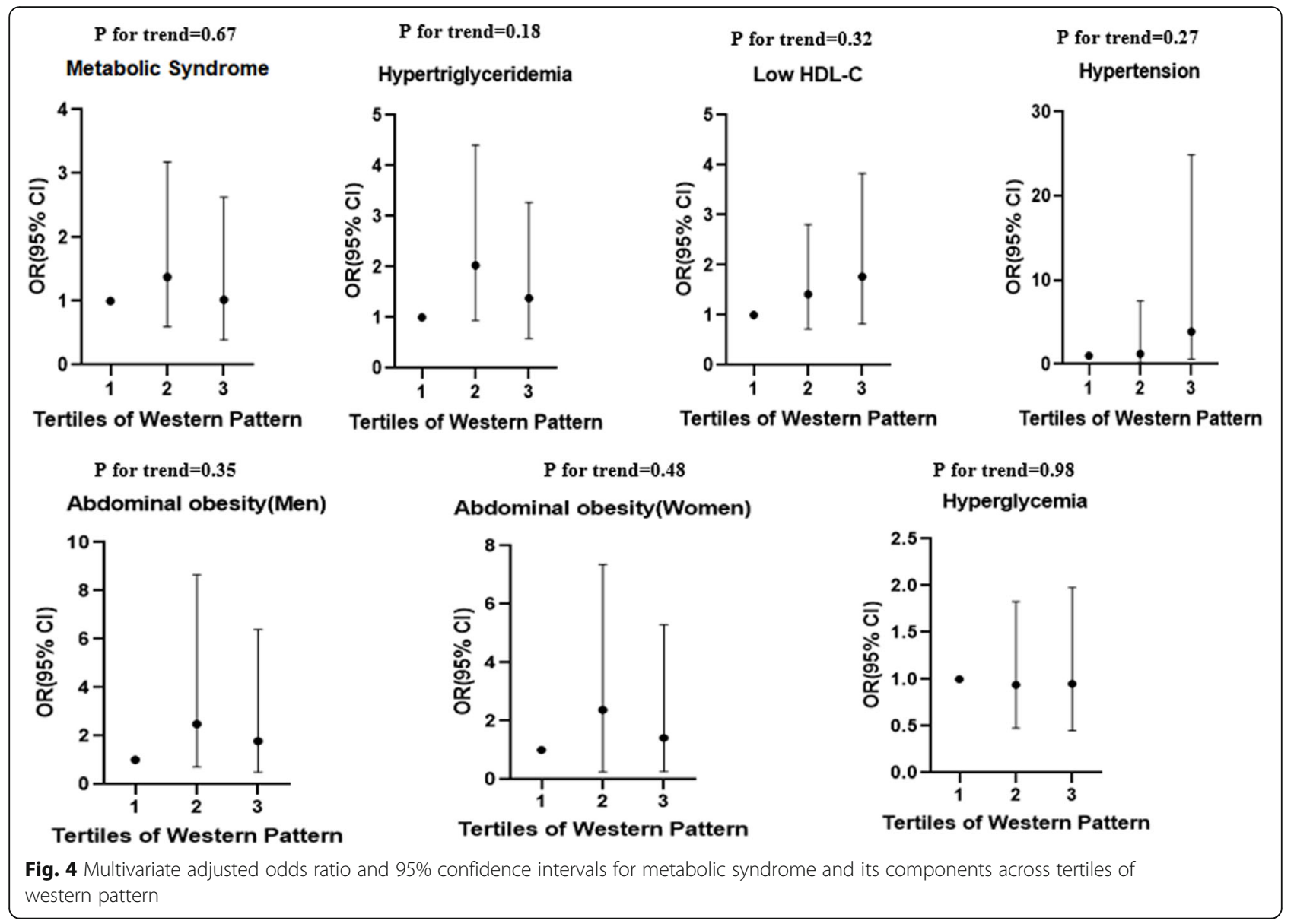

Table 5 Multivariate adjusted odds ratios and 95\% confidence intervals for interaction between CRF and dietary pattern with metabolic syndrome

\begin{tabular}{lllll}
\hline CRF & \multicolumn{4}{l}{ Tertiles of healthy dietary pattern } \\
& T1 & T2 & T3 & $P_{\text {value for interaction }}$ \\
T1 & 1.00 & 1.00 & 1.00 & 0.69 \\
T2 & 1.00 & $0.85(0.14,5.06)$ & $1.85(0.29,11.70)$ & \\
T3 & 1.00 & $0.57(0.09,3.53)$ & $0.43(0.05,3.22)$ & \\
CRF & Tertiles of mixed dietary pattern & $P_{\text {value for interaction }}$ \\
& T1 & T2 & T3 & 0.80 \\
T1 & 1.00 & 1.00 & 1.00 & \\
T2 & 1.00 & $1.54(0.19,12.07)$ & $1.32(0.16,10.48)$ & \\
T3 & 1.00 & $1.36(0.17,10.91)$ & $0.47(0.05,4.28)$ & \\
CRF & Tertiles of western dietary pattern & $P_{\text {value for interaction }}$ \\
& T1 & T2 & T3 & 0.60 \\
T1 & 1.00 & 1.00 & 1.00 & \\
T2 & 1.00 & $0.58(0.09,3.54)$ & $1.60(0.25,10.21)$ & \\
T3 & 1.00 & $1.36(0.21,8.72)$ & $0.76(0.09,6.23)$ & \\
\hline
\end{tabular}

Data are presented as OR $(95 \% \mathrm{Cl})$

CRF cardiorespiratory fitness decreased odds of MetS, however, were not statistically significant. Also, higher CRF levels were associated with lower measures of abdominal obesity. Several studies have investigated the associations of CRF and MetS. Shaibi et al. indicated that CRF was not associated with any individual risk factor of the metabolic syndrome [52]. In addition, a population-based cohort on 605 middle-aged men and women found no independent association between CRF and the development of MetS [53]. In contrast, Ekelund et al. reported significant reverse association between CRF and with indicators of insulin resistance, hyperglycemia, hyperlipidemia, and clustered metabolic risk in children [54]. Other studies have shown that CRF is linked to insulin sensitivity as a risk factor for MetS [55, 56]. Hassinen et al., in 1226 men and women aged 57-78 years, reported that higher levels of CRF protect against MetS [9]. Increased muscle insulin sensitivity, lipoprotein lipase activity in active musculoskeletal, transport of lipids and lipoproteins from the peripheral blood circulation and tissues to the liver, and reduction abdominal obesity [57] are mechanisms by which MetS may improve with fitness $[58,59]$. The differences between the results of the association between CRF and MetS in different studies may be 
Table 6 Multivariate adjusted means for interaction between CRF and dietary patterns with metabolic syndrome components

FBS ( $\mathbf{m g} / \mathbf{d l})$
Tertiles of healthy pattern
T1
T2
T3
FBS ( $\mathbf{m g} / \mathbf{d l})$
Tertiles of mixed pattern
T1
T2
T3
FBS ( $\mathbf{m g} / \mathbf{d l})$
Tertiles of western pattern
T1
T2
T3
TG ( $\mathbf{m g} / \mathbf{d l})$

Tertiles of healthy pattern

$\mathrm{T} 1$

$\mathrm{T} 2$

T3

\section{TG (mg/dl)}

Tertiles of mixed pattern

$\mathrm{T} 1$

T2

$\mathrm{T} 3$

\section{TG (mg/dl)}

Tertiles of western pattern

$\mathrm{T} 1$

$\mathrm{T} 2$

T3

\section{HDL (mg/dl)}

Tertiles of healthy pattern

$\mathrm{T} 1$

T2

T3

\section{HDL (mg/dl)}

Tertiles of mixed pattern

$\mathrm{T} 1$

$\mathrm{T} 2$

T3

\section{HDL (mg/dl)}

Tertiles of western pattern

$$
\text { T1 }
$$

$\mathrm{T} 2$

T3

\section{WC $(\mathrm{cm})$}

Tertiles of healthy pattern

$$
\text { T1 }
$$$$
\mathrm{T} 2
$$

CRF (ml/kg/min)

$\mathrm{T} 1$

$98.0 \pm 11.8$

$97.6 \pm 7.25$

$96.8 \pm 9.58$

CRF (ml $/ \mathrm{kg} / \mathrm{min})$

$\mathrm{T} 1$

$97.5 \pm 13.4$

$98.3 \pm 9.85$

$96.6 \pm 7.41$

CRF (ml/ $\mathrm{kg} / \mathrm{min})$

$\mathrm{T} 1$

$98.7 \pm 7.94$

$97.1 \pm 9.72$

$96.0 \pm 12.8$

CRF (ml $/ \mathrm{kg} / \mathrm{min})$

T1

$110 \pm 47.2$

$138 \pm 65.7$

$126 \pm 70.7$

CRF $(\mathrm{ml} / \mathrm{kg} / \mathrm{min})$

$\mathrm{T} 1$

$129 \pm 87.9$

$118 \pm 46.0$

$125 \pm 56.4$

CRF (ml/ $\mathrm{kg} / \mathrm{min})$

$\mathrm{T} 1$

$109 \pm 45.6$

$135 \pm 63.4$

$133 \pm 77.5$

CRF $(\mathrm{ml} / \mathrm{kg} / \mathrm{min})$

$\mathrm{T} 1$

$49.5 \pm 8.56$

$51.5 \pm 10.0$

$48.3 \pm 9.38$

CRF $(\mathrm{ml} / \mathrm{kg} / \mathrm{min})$

$\mathrm{T} 1$

$50.3 \pm 9.26$

$51.6 \pm 9.55$

$47.7 \pm 8.80$

CRF $(\mathrm{ml} / \mathrm{kg} / \mathrm{min})$

$\mathrm{T} 1$

$51.9 \pm 9.73$

$47.8 \pm 7.80$

$48.6 \pm 9.76$

CRF $(\mathrm{ml} / \mathrm{kg} / \mathrm{min})$

$\mathrm{T} 1$

$90.3 \pm 13.8$

$94.5 \pm 13.6$

\section{$\mathrm{T} 2$}

$100 \pm 14.0$

$94.6 \pm 8.09$

$106 \pm 48.1$

$\mathrm{T} 2$

$104.5 \pm 42.0$

$97.8 \pm 10.3$

$96.6 \pm 10.7$

$\mathrm{T} 2$

$97.9 \pm 8.05$

$95.5 \pm 13.0$

$106 \pm 44.0$

$\mathrm{T} 2$

$127 \pm 80.6$

$133 \pm 90.5$

$115 \pm 66.2$

$\mathrm{T} 2$

$109 \pm 64.0$

$146 \pm 86.4$

$126 \pm 90.8$

$\mathrm{T} 2$

$121 \pm 63.5$

$136.6 \pm 91.4$

$119 \pm 81.0$

$\mathrm{T} 2$

$47.1 \pm 11.0$

$49.7 \pm 13.4$

$51.7 \pm 11.5$

$\mathrm{T} 2$

$49.1 \pm 10.0$

$48.7 \pm 13.9$

$50.8 \pm 12.7$

$\mathrm{T} 2$

$47.6 \pm 11.2$

$49.0 \pm 13.2$

$51.3 \pm 11.6$

$\mathrm{T} 2$

$86.0 \pm 11.0$

$88.9 \pm 12.9$
T3

$96.4 \pm 9.63$

$98.1 \pm 14.5$

$97.6 \pm 18.1$

T3

$99.3 \pm 16.8$

$97.7 \pm 11.0$

$95.1 \pm 15.9$

T3

$96.7 \pm 10.6$

$99.1 \pm 14.7$

$96.8 \pm 17.8$

T3

$114 \pm 70.8$

$125 \pm 83.3$

$94.1 \pm 41.4$

T3

$117 \pm 64.0$

$110 \pm 79.1$

$101 \pm 56.4$

T3

$93.9 \pm 57.3$

$115 \pm 65.3$

$117 \pm 73.1$

$\mathrm{T} 3$

$50.9 \pm 12.6$

$51.5 \pm 11.4$

$48.0 \pm 8.66$

$\mathrm{T} 3$

$49.4 \pm 10.1$

$51.1 \pm 12.5$

$49.5 \pm 9.99$

T3

$48.0 \pm 8.19$

$54.2 \pm 11.8$

$48.0 \pm 10.8$

$\mathrm{T} 3$

$84.1 \pm 10.4$

$85.5 \pm 11.2$
$P_{\text {value }}$

0.45

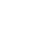

$P_{\text {value }}$

0.86

$P_{\text {value }}$

0.22

$P_{\text {value }}$

0.66

$P_{\text {value }}$

0.27

$P_{\text {value }}$

0.84

$P_{\text {value }}$

0.39

$P_{\text {value }}$

0.65

$P_{\text {value }}$

0.03

value

0.78 
Table 6 Multivariate adjusted means for interaction between CRF and dietary patterns with metabolic syndrome components (Continued)

\begin{tabular}{|c|c|c|c|c|}
\hline T3 & $96.3 \pm 12.9$ & $94.5 \pm 13.4$ & $87.3 \pm 9.47$ & \\
\hline WC (cm) & CRF (ml/kg/min) & & & \\
\hline Tertiles of mixed pattern & $\mathrm{T} 1$ & $\mathrm{~T} 2$ & $\mathrm{~T} 3$ & $P_{\text {value }}$ \\
\hline $\mathrm{T} 1$ & $92.0 \pm 15.2$ & $88.7 \pm 12.3$ & $85.1 \pm 9.35$ & 0.05 \\
\hline $\mathrm{T} 2$ & $89.2 \pm 13.8$ & $88.7 \pm 13.6$ & $88.7 \pm 10.0$ & \\
\hline T3 & $98.0 \pm 11.2$ & $91.9 \pm 12.6$ & $84.1 \pm 11.3$ & \\
\hline WC $(\mathrm{cm})$ & $\operatorname{CRF}(\mathrm{ml} / \mathrm{kg} / \mathrm{min})$ & & & \\
\hline Tertiles of western pattern & $\mathrm{T} 1$ & $\mathrm{~T} 2$ & $\mathrm{~T} 3$ & $P_{\text {value }}$ \\
\hline $\mathrm{T} 1$ & $91.8 \pm 11.7$ & $86.4 \pm 10.7$ & $87.0 \pm 9.26$ & 0.32 \\
\hline $\mathrm{T} 2$ & $91.6 \pm 15.6$ & $90.7 \pm 15.0$ & $83.5 \pm 10.4$ & \\
\hline $\mathrm{T} 3$ & $98.3 \pm 13.2$ & $90.9 \pm 11.6$ & $86.9 \pm 10.8$ & \\
\hline SBP $(\mathrm{mmHg})$ & $\operatorname{CRF}(\mathrm{ml} / \mathrm{kg} / \mathrm{min})$ & & & \\
\hline Tertiles of healthy pattern & $\mathrm{T} 1$ & $\mathrm{~T} 2$ & $\mathrm{~T} 3$ & $P_{\text {value }}$ \\
\hline $\mathrm{T} 1$ & $99.0 \pm 39.0$ & $108 \pm 11.9$ & $115 \pm 13.4$ & 0.03 \\
\hline $\mathrm{T} 2$ & $113.0 \pm 13.4$ & $108 \pm 9.23$ & $111 \pm 9.71$ & \\
\hline $\mathrm{T} 3$ & $115.7 \pm 16.9$ & $119 \pm 17.1$ & $115 \pm 10.4$ & \\
\hline $\mathrm{SBP}(\mathrm{mmHg})$ & $\mathrm{CRF}(\mathrm{ml} / \mathrm{kg} / \mathrm{min})$ & & & \\
\hline Tertiles of mixed pattern & $\mathrm{T} 1$ & $\mathrm{~T} 2$ & $\mathrm{~T} 3$ & $P_{\text {value }}$ \\
\hline $\mathrm{T} 1$ & $99.3 \pm 32.6$ & $111 \pm 9.88$ & $113 \pm 11.6$ & 0.12 \\
\hline $\mathrm{T} 2$ & $108 \pm 28.7$ & $107 \pm 15.6$ & $117 \pm 11.3$ & \\
\hline T3 & $113 \pm 24.0$ & $117 \pm 14.8$ & $112 \pm 10.1$ & \\
\hline SBP $(\mathrm{mmHg})$ & CRF (ml/kg/min) & & & \\
\hline Tertiles of western pattern & $\mathrm{T} 1$ & $\mathrm{~T} 2$ & $\mathrm{~T} 3$ & $P_{\text {value }}$ \\
\hline $\mathrm{T} 1$ & $114 \pm 24.2$ & $110 \pm 11.7$ & $117 \pm 10.9$ & 0.26 \\
\hline $\mathrm{T} 2$ & $106 \pm 29.7$ & $112 \pm 14.9$ & $111 \pm 10.3$ & \\
\hline $\mathrm{T} 3$ & $100 \pm 31.2$ & $111 \pm 14.2$ & $114 \pm 11.3$ & \\
\hline $\mathrm{DBP}(\mathrm{mmHg})$ & CRF (ml/kg/min) & & & \\
\hline Tertiles of healthy pattern & $\mathrm{T} 1$ & $\mathrm{~T} 2$ & $\mathrm{~T} 3$ & $P_{\text {value }}$ \\
\hline $\mathrm{T} 1$ & $69.8 \pm 14.1$ & $69.8 \pm 10.9$ & $69.7 \pm 9.06$ & 0.78 \\
\hline $\mathrm{T} 2$ & $70.2 \pm 10.1$ & $68.5 \pm 13.3$ & $70.5 \pm 6.84$ & \\
\hline T3 & $74.0 \pm 11.6$ & $72.7 \pm 10.4$ & $70.5 \pm 7.59$ & \\
\hline $\mathrm{DBP}(\mathrm{mmHg})$ & CRF (ml/kg/min) & & & \\
\hline Tertiles of mixed pattern & $\mathrm{T} 1$ & $\mathrm{~T} 2$ & $\mathrm{~T} 3$ & $P_{\text {value }}$ \\
\hline $\mathrm{T} 1$ & $69.0 \pm 9.13$ & $69.4 \pm 9.60$ & $70.5 \pm 6.46$ & $<0.01$ \\
\hline $\mathrm{T} 2$ & $68.0 \pm 13.6$ & $66.8 \pm 14.5$ & $73.1 \pm 6.43$ & \\
\hline $\mathrm{T} 3$ & $75.4 \pm 11.5$ & $75.5 \pm 9.09$ & $67.4 \pm 9.21$ & \\
\hline $\mathrm{DBP}(\mathrm{mmHg})$ & CRF (ml/kg/min) & & & \\
\hline Tertiles of western pattern & $\mathrm{T} 1$ & $\mathrm{~T} 2$ & $\mathrm{~T} 3$ & $P_{\text {value }}$ \\
\hline $\mathrm{T} 1$ & $70.9 \pm 15.1$ & $66.0 \pm 14.7$ & $72.5 \pm 6.56$ & 0.13 \\
\hline $\mathrm{T} 2$ & $71.5 \pm 9.16$ & $71.1 \pm 9.75$ & $67.9 \pm 6.98$ & \\
\hline $\mathrm{T} 3$ & $71.2 \pm 10.8$ & $72.6 \pm 10.5$ & $70.6 \pm 8.62$ & \\
\hline
\end{tabular}

$P$ value less than 0.05 was considered significant Data are presented as mean \pm standard deviation $P_{\text {value }}$ derived from two-way analysis of variances

CRF cardiorespiratory fitness, FBS Fasting Blood Sugar, TG Triglyceride, HDL High Density Lipoprotein, SBP Systolic Blood Pressure, DBP Diastolic Blood, WC Waist Circumference, $\mathrm{mg} / \mathrm{dl}$ miligram per deciliter, $\mathrm{cm}^{2}$ centimeter ${ }^{2}, \mathrm{mmHg}$ millimetre of mercury, $\mathrm{ml} / \mathrm{kg} / \mathrm{min}$ milliliter per kilogram per minute

related to different sample sizes, group characteristics, and differences in study methods. In addition, genetic, age, body composition, and most importantly, physical activity determines CRF [60]. In this study, subjects who have top levels of CRF have more physical activity, have greater FFM, lower BMI, WC, and WHR than those 
who have lower level of CRF. Indeed, CRF moderates the link between obesity and metabolic status [61]; considering that the risk of metabolic disorders, including MetS, increases with obesity.

All of these articles separately evaluated the association between dietary pattern and cardiorespiratory fitness on metabolic syndrome. To our knowledge, just three previous studies have examined the combined association between the dietary pattern and CRF with MetS. Kouki et al., in a sample of 663 men and 671 women 57-78 years of age revealed healthy diet, and higher levels of CRF are associated with a reduced risk of having MetS [62]. A cross-sectional school-based study was conducted on 468 adolescents aged 15-18, suggested the chances of having MetS are significantly higher among adolescents with low adherence to the Southern European Atlantic Diet (SEADiet) which has emerged as a healthy dietary pattern compared with adolescents with higher adherence to SEADiet [63]. Liao et al., in a cross-sectional study among 615 children (354 boys and 261 girls) aged $9.6 \pm 0.6$ years reported a significantly interactive relationship between high CRF and healthy dietary intake with metabolic health among Chinese children [64]. The results of these studies suggested that a combination of diet and CRF may have synergistic effects on metabolic health. Results from the current study showed that there was no significant interaction between CRF and HDP, MDP, and WDP with odds of MetS. The conflicting results between our study and the studies mentioned above may be due to differences in socio-demographic characteristics, ethnicity, behavioral and lifestyle factors, differences in study population, and differences in dietary data collection methods.

In this study, follow to HDP showed a significant increase for systolic blood pressure across tertiles of CRF. Interestingly, some people develop high blood pressure notwithstanding an active physical lifestyle or a healthy diet, while some sedentary people with unhealthy dietary patterns may have optimal blood pressure. A number of studies have shown that higher cardiorespiratory fitness and physical activity are associated with lower blood pressure $[65,66]$. However, some studies did not find a connection [67] and in some cases, it is even accompanied by a scant increase [60]. The two chief factors that can lead to these differences are the level of primary phenotype and familial aggregation [60]. In general, information on the contribution of genetic diversity to the antihypertensive effect associated with cardiorespiratory fitness is low. In this study, more adherence to the MDP was associated with an increase in waist circumference and blood pressure. But in people who have a MDP, waist circumference and diastolic blood pressure decreased with increasing physical activity and cardiorespiratory fitness. Physical activity decreased the effect of genetic factors like FTO genotype to cause high BMI and WC [68]. Eventually, high cardiorespiratory fitness overcame the harmful effects of a mixed dietary pattern on WC and DBP. In relation to the interaction of western dietary pattern and cardiovascular fitness with the components of MetS it is notable that, despite have reported that HDL-C is highly responsive in exercise and have ascertained that exercise and high level of cardiorespiratory fitness increase HDL-cholesterol [69] adherence to WDP showed a significant decrease for HDL across tertiles of CRF. In many studies, the western dietary pattern was inversely associated with HDL-C [70, 71]. One mechanism clarifying the association between the WDP and lower HDL-C could be higher intake of refined carbohydrates among participants who follow the WDP [71]. Finally, western dietary pattern dominates the detrimental effects of a cardiorespiratory fitness on HDL-C.

Our study had some strengths. According to our knowledge, that interaction between three major dietary patterns and cardiorespiratory fitness on metabolic syndrome is reported for the first time in our study. We used a 168-item questionnaire and reduced the potential for residual confusion by collecting comprehensive dietary information. However, it should be mentioned that present study had some limitations owing to the crosssectional design prevent any causal conclusion between diet, CRF, and metabolic syndrome being distinguished. Also, Residual disruptors that are unmeasurable and possible in observational studies could affect the study. Finally, it is important to note that the findings of this study may not be generalize to beyond this sample of adults.

\section{Conclusion}

Overall, adherence to identified dietary patterns in this population was associated with some components of MetS. However, nor CRF neither the combination of dietary patterns and CRF was related to the odds of MetS among Iranian adults. More studies are needed to clarify these associations and to consider environmental and interpersonal determinants. However, due to the cross-sectional design of the present study, more longitudinal studies are needed for more accurate conclusions.

\section{Abbreviations}

HDP: Healthy Dietary Pattern; MDP: Mixed Dietary Pattern; WDP: Western Dietary Pattern; CRF: Cardiorespiratory Fitness; FBS: Fasting Blood Sugar; TC: Total Cholesterol; TG: Triglyceride; HDL-C: High Density Lipoprotein; LDLC: Low Density Lipoprotein; SBP: Systolic Blood Pressure; DBP: Diastolic Blood Pressure; FFM: Fat Free Mass; FM: Fat Mass; WC: Waist Circumference; CVD: cardiovascular disease; WHR: waist to hip ratio; BMI: Body Mass Index 


\section{Supplementary Information}

The online version contains supplementary material available at https://doi. org/10.1186/s12937-021-00695-4

Additional file 1: Supplementary figure 1. Scree plot of $25 \mathrm{food}$ groups according ti its eigenvalues

\section{Acknowledgments}

Authors thank all those who participated in this study.

\section{Authors' contributions}

SSb contributed to conception/design of the research; MGH, MSH and NP contributed to acquisition, analysis, or interpretation of the data; $\mathrm{HSH}$ and $\mathrm{CC}$ drafted the manuscript; KD and SSb critically revised the manuscript, and SS$b$ agrees to be fully accountable for ensuring the integrity and accuracy of the work. All authors read and approved the final manuscript.

\section{Funding}

None.

\section{Availability of data and materials}

The datasets generated or analyzed during the current study are not publicly available but are available from the corresponding author on reasonable request.

\section{Declarations}

\section{Ethics approval and consent to participate}

This study was conducted according to the guidelines laid down in the Declaration of Helsinki and all procedures involving research study participants were approved by the ethics committee of Tehran University of Medical Sciences (TUMS.VCR.REC.1396.4085). Written informed consent was obtained from all subjects/patients.

\section{Consent for publication}

Participants were provided a study overview and verbal consent was attained

\section{Competing interests}

The authors declare that they have no competing interests.

\section{Author details}

'Department of Community Nutrition, School of Nutritional Sciences and Dietetics, Tehran University of Medical Sciences (TUMS), No 44, Hojjat-dost Alley, Naderi St., Keshavarz Blvd, Tehran, Iran. ${ }^{2}$ Department of Clinical Nutrition, School of Nutritional Sciences and Dietetics, Tehran University of Medical Sciences (TUMS), Tehran, Iran. ${ }^{3}$ Centre for Sport, Exercise, and Life Sciences, Coventry University, Coventry CV15FB, UK.

Received: 26 August 2020 Accepted: 5 April 2021

Published online: 13 April 2021

\section{References}

1. Grundy SM. Metabolic syndrome update. Trends Cardiovasc Med. 2016; 26(4):364-73. https://doi.org/10.1016/j.tcm.2015.10.004.

2. Mirmiran P, Ziadlou M, Karimi S, Hosseini-Esfahani F. The association of dietary patterns and adherence to WHO healthy diet with metabolic syndrome in children and adolescents: Tehran lipid and glucose study. BMC Public Health. 2019;19(1):1457. https://doi.org/10.1186/s12889-019-7779-9.

3. Hageman PA, Pullen $\mathrm{CH}$, Hertzog M, Boeckner LS, Walker SN. Associations of cardiorespiratory fitness and fatness with metabolic syndrome in rural women with prehypertension. J Obes. 2012;2012:618728. https://doi.org/1 0.1155/2012/618728.PMC3512333.

4. Monnerie S, Comte B, Ziegler D, Morais JA, Pujos-Guillot E, Gaudreau P. Metabolomic and Lipidomic signatures of metabolic syndrome and its physiological components in adults: a systematic review. Sci Rep. 2020;10(1): 669. https://doi.org/10.1038/s41598-019-56909-7.PMC6971076.

5. Myers J, Kokkinos P, Nyelin E. Physical Activity, Cardiorespiratory Fitness, and the Metabolic Syndrome. Nutrients. 2019;11(7). https://doi.org/10.3390/nu11 071652.PMC6683051.
6. Wildman RP, Muntner P, Reynolds K, McGinn AP, Rajpathak S, Wylie-Rosett J, et al. The obese without cardiometabolic risk factor clustering and the normal weight with cardiometabolic risk factor clustering: prevalence and correlates of 2 phenotypes among the US population (NHANES 1999-2004). Arch Intern Med. 2008;168(15):1617-24. https://doi.org/10.1001/archinte.168.15.1617.

7. Church TS, Earnest CP, Skinner JS, Blair SN. Effects of different doses of physical activity on cardiorespiratory fitness among sedentary, overweight or obese postmenopausal women with elevated blood pressure: a randomized controlled trial. Jama. 2007;297(19):2081-91. https://doi.org/10.1 001/jama.297.19.2081.

8. LaMonte MJ, Barlow CE, Jurca R, Kampert JB, Church TS, Blair SN. Cardiorespiratory fitness is inversely associated with the incidence of metabolic syndrome: a prospective study of men and women. Circulation. 2005;112(4):505-12. https://doi.org/10.1161/circulationaha.104.503805.

9. Hassinen M, Lakka TA, Savonen K, Litmanen H, Kiviaho L, Laaksonen DE, et al. Cardiorespiratory fitness as a feature of metabolic syndrome in older men and women: the dose-responses to exercise training study (DR's EXTRA). Diabetes Care. 2008;31(6):1242-7. https://doi.org/10.2337/dc07-2298.

10. Duncan GE. Exercise, fitness, and cardiovascular disease risk in type 2 diabetes and the metabolic syndrome. Curr Diab Rep. 2006;6(1):29-35. https://doi.org/10.1007/s1 1892-006-0048-1.

11. Kaminsky LA, Arena R, Ellingsen $\varnothing$, Harber MP, Myers J, Ozemek C, et al. Cardiorespiratory fitness and cardiovascular disease - the past, present, and future. Prog Cardiovasc Dis. 2019;62(2):86-93. https://doi.org/10.1016/.jpca d.2019.01.002.

12. Vancampfort D, Mugisha J, Rosenbaum S, Firth J, De Hert M, Probst M, et al. Cardiorespiratory fitness levels and moderators in people with HIV: a systematic review and meta-analysis. Prev Med. 2016;93:106-14. https://doi. org/10.1016/j.ypmed.2016.10.001

13. Vancampfort D, Ward PB, Stubbs B. Physical fitness levels and moderators in people with epilepsy: a systematic review and meta-analysis. Epilepsy Behav. 2019;99:106448. https://doi.org/10.1016/j.yebeh.2019.106448.

14. Santi-Cano MJ, Novalbos-Ruiz JP, Bernal-Jiménez M, Bibiloni MDM, Tur JA, Rodriguez Martin A. Association of Adherence to Specific Mediterranean Diet Components and Cardiorespiratory Fitness in Young Adults. Nutrients. 2020;12(3). https://doi.org/10.3390/nu12030776.PMC7146290.

15. Lee DC, Sui X, Church TS, Lavie CJ, Jackson AS, Blair SN. Changes in fitness and fatness on the development of cardiovascular disease risk factors hypertension, metabolic syndrome, and hypercholesterolemia. J Am Coll Cardiol. 2012;59(7): 665-72. https://doi.org/10.1016/j.jacc.2011.11.013.PMC3293498.

16. Shikany JM, Jacobs DR Jr, Lewis CE, Steffen LM, Sternfeld B, Carnethon MR et al. Associations between food groups, dietary patterns, and cardiorespiratory fitness in the coronary artery risk development in young adults study. Am J Clin Nutr. 2013;98(6):1402-9. https://doi.org/10.3945/a jcn.113.058826.Pmc3831533.

17. Howe AS, Skidmore PM, Parnell WR, Wong JE, Lubransky AC, Black KE. Cardiorespiratory fitness is positively associated with a healthy dietary pattern in New Zealand adolescents. Public Health Nutr. 2016;19(7):1279-87. https://doi.org/10.1017/s1368980015002566

18. Archundia Herrera MC, Subhan FB, Chan CB. Dietary patterns and cardiovascular disease risk in people with type 2 diabetes. Curr Obes Rep. 2017;6(4):405-13. https://doi.org/10.1007/s13679-017-0284-5.

19. Seyedi SHS, Mottaghi A, Mirmiran P, Hedayati M, Azizi F. The relationship between dietary patterns and lipoprotein-associated phospholipase A2 levels in adults with cardiovascular risk factors: Tehran lipid and glucose study. J Res Med Sci. 2020;25:3. https://doi.org/10.4103/jrms.JRMS_256_19. PMC7003539.

20. Neuhouser ML, Howard B, Lu J, Tinker LF, Van Horn L, Caan B, et al. A lowfat dietary pattern and risk of metabolic syndrome in postmenopausal women: the Women's Health Initiative. Metabolism. 2012;61(11):1572-81. https://doi.org/10.1016/j.metabol.2012.04.007.PMC3430820.

21. Menotti A, Alberti-Fidanza A, Fidanza F, Lanti M, Fruttini D. Factor analysis in the identification of dietary patterns and their predictive role in morbid and fatal events. Public Health Nutr. 2012;15(7):1232-9. https://doi.org/10.1017/ S1368980011003235

22. Abbasalizad Farhangi $M$, Vajdi M, Nikniaz L, Nikniaz Z. The interaction between dietary inflammatory index and 6 P21 rs2010963 gene variants in metabolic syndrome. Eat Weight Disord. 2020;25(4):1049-60. https://doi. org/10.1007/s40519-019-00729-1.

23. Moore BF, Clark ML, Bachand A, Reynolds SJ, Nelson TL, Peel JL. Interactions between diet and exposure to secondhand smoke on metabolic syndrome 
among children: NHANES 2007-2010. J Clin Endocrinol Metab. 2016;101(1): 52-8. https://doi.org/10.1210/jc.2015-2477.

24. Mirzababaei A, Mollahosseini M, Rahimi MH, Yekaninejad MS, Maghbooli Z, Sobhani R, et al. Interaction between a variant of chromosome 9p21.3 locus and diet antioxidant capacity on metabolic syndrome in Tehrani adults. Diabetol Metab Syndr. 2018;10:76. https://doi.org/10.1186/s13098-018-0372z.PMC6194558

25. Maintinguer Norde M, Oki E, Ferreira Carioca AA, Teixeira Damasceno NR, Fisberg RM, Lobo Marchioni DM, et al. Influence of IL1B, IL6 and IL10 gene variants and plasma fatty acid interaction on metabolic syndrome risk in a cross-sectional population-based study. Clin Nutr. 2018;37(2):659-66. https:// doi.org/10.1016/j.clnu.2017.02.009.

26. Floegel A, Wientzek A, Bachlechner U, Jacobs S, Drogan D, Prehn C, et al. Linking diet, physical activity, cardiorespiratory fitness and obesity to serum metabolite networks: findings from a population-based study. Int J Obes. 2014;38(11):1388-96. https://doi.org/10.1038/ijo.2014.39.Pmc4229626.

27. Moghaddam MB, Aghdam FB, Jafarabadi MA, Allahverdipour H, Nikookheslat SD, Safarpour S. The Iranian version of international physical activity questionnaire (IPAQ) in Iran: content and construct validity, factor structure, internal consistency and stability. World Appl Sci J. 2012;18(8): 1073-80.

28. Wareham NJ, Jakes RW, Rennie KL, Schuit J, Mitchell J, Hennings S, et al. Validity and repeatability of a simple index derived from the short physical activity questionnaire used in the European prospective investigation into Cancer and nutrition (EPIC) study. Public Health Nutr. 2003;6(4):407-13. https://doi.org/10.1079/phn2002439.

29. Mirmiran P, Esfahani FH, Mehrabi Y, Hedayati M, Azizi F. Reliability and relative validity of an FFQ for nutrients in the Tehran lipid and glucose study. Public Health Nutr. 2010;13(5):654-62. https://doi.org/10.1017/s13 68980009991698.

30. Korth O, Bosy-Westphal A, Zschoche P, Gluer CC, Heller M, Muller MJ. Influence of methods used in body composition analysis on the prediction of resting energy expenditure. Eur J Clin Nutr. 2007;61(5):582-9. https://doi. org/10.1038/sj.ejcn.1602556.

31. Executive Summary of The Third Report of The National Cholesterol Education Program (NCEP) Expert Panel on Detection, Evaluation, And Treatment of High Blood Cholesterol In Adults (Adult Treatment Panel III). JAMA. 2001;285(19):2486-97. https://doi.org/10.1001/jama.285.19.2486.

32. Bruce RA, Kusumi F, Hosmer D. Maximal oxygen intake and nomographic assessment of functional aerobic impairment in cardiovascular disease. Am Heart J. 1973;85(4):546-62. https://doi.org/10.1016/0002-8703(73)90502-4.

33. Hu FB, Rimm E, Smith-Warner SA, Feskanich D, Stampfer MJ, Ascherio A, et al. Reproducibility and validity of dietary patterns assessed with a foodfrequency questionnaire. Am J Clin Nutr. 1999;69(2):243-9. https://doi.org/1 0.1093/ajcn/69.2.243

34. Esmaillzadeh A, Kimiagar M, Mehrabi Y, Azadbakht L, Hu FB, Willett WC. Dietary patterns, insulin resistance, and prevalence of the metabolic syndrome in women. Am J Clin Nutr. 2007;85(3):910-8. https://doi.org/10.1 093/ajcn/85.3.910

35. Esmaillzadeh A, Azadbakht L. Major dietary patterns in relation to general obesity and central adiposity among Iranian women. J Nutr. 2008;138(2): 358-63. https://doi.org/10.1093/jn/138.2.358.

36. Kim J-O, Mueller CW. Factor analysis: Statistical methods and practical issues: New York: SAGE publications; 1978

37. Cho YA, Kim J, Cho ER, Shin A. Dietary patterns and the prevalence of metabolic syndrome in Korean women. Nutr Metab Cardiovasc Dis. 2011; 21(11):893-900. https://doi.org/10.1016/j.numecd.2010.02.018.

38. Williams DE, Prevost AT, Whichelow MJ, Cox BD, Day NE, Wareham NJ. A cross-sectional study of dietary patterns with glucose intolerance and other features of the metabolic syndrome. Br J Nutr. 2000;83(3):257-66. https:// doi.org/10.1017/S0007114500000337.

39. Lutsey PL, Steffen LM, Stevens J. Dietary intake and the development of the metabolic syndrome. Circulation. 2008;117(6):754-61. https://doi.org/10.11 61/CIRCULATIONAHA.107.716159.

40. Sonnenberg L, Pencina M, Kimokoti R, Quatromoni P, Nam BH, D'agostino R, et al. Dietary patterns and the metabolic syndrome in obese and non-obese Framingham women. Obes Res. 2005;13(1):153-62. https://doi.org/10.1038/ oby.2005.20

41. Muzio F, Mondazzi L, Harris WS, Sommariva D, Branchi A. Effects of moderate variations in the macronutrient content of the diet on cardiovascular disease risk factors in obese patients with the metabolic syndrome. Am J Clin Nutr. 2007;86(4):946-51. https://doi.org/10.1093/ajcn/ 86.4.946.

42. Baxter AJ, Coyne T, McClintock C. Dietary patterns and metabolic syndromea review of epidemiologic evidence. Asia Pac J Clin Nutr. 2006;15(2):134-42.

43. Lutsey PL, Steffen LM, Stevens J. Dietary intake and the development of the metabolic syndrome: the atherosclerosis risk in communities study. Circulation. 2008;117(6):754-61. https://doi.org/10.1161/circulationaha.107.716159.

44. Eshtiaghi R, Esteghamati A, Nakhjavani M. Menopause is an independent predictor of metabolic syndrome in Iranian women. Maturitas. 2010;65(3): 262-6. https://doi.org/10.1016/j.maturitas.2009.11.004.

45. Cho GJ, Lee JH, Park HT, Shin JH, Hong SC, Kim T, et al. Postmenopausal status according to years since menopause as an independent risk factor for the metabolic syndrome. Menopause. 2008;15(3):524-9. https://doi.org/1 0.1097/gme.0b013e3181559860.

46. Poehlman ET, Toth MJ, Gardner AW. Changes in energy balance and body composition at menopause: a controlled longitudinal study. Ann Intern Med. 1995;123(9):673-5. https://doi.org/10.7326/0003-4819-123-9-19951101 0-00005.

47. Ramírez-Vélez R, Correa-Bautista JE. Percentage of Body Fat and Fat Mass Index as a Screening Tool for Metabolic Syndrome Prediction in Colombian University Students. Nutrients. 2017;9(9). https://doi.org/10.3390/nu9091009.

48. Kim K, Park SM. Association of muscle mass and fat mass with insulin resistance and the prevalence of metabolic syndrome in Korean adults: a cross-sectional study. Sci Rep. 2018;8(1):2703. https://doi.org/10.1038/s41598018-21168-5.Pmc5807388.

49. Knowles KM, Paiva LL, Sanchez SE, Revilla L, Lopez T, Yasuda MB, et al. Waist circumference, body mass index, and other measures of adiposity in predicting cardiovascular disease risk factors among Peruvian adults. Int J Hypertens. 2011;2011:931402. https://doi.org/10.4061/2011/931402.Pmc3034 939.

50. Koh JH, Lee MY, Nam SM, Sung JK, Jung PM, Noh JK, et al. Relationship between menopausal status and metabolic syndrome components in Korean women. Korean Diabetes J. 2008;32(3):243-51. https://doi.org/10.4 093/kdj.2008.32.3.243.

51. Jouyandeh Z, Nayebzadeh F, Qorbani M, Asadi M. Metabolic syndrome and menopause. J Diabetes Metab Disord. 2013;12(1):1. https://doi.org/10.11 86/2251-6581-12-1.Pmc3598172.

52. Shaibi GQ, Cruz ML, Ball GD, Weigensberg MJ, Kobaissi HA, Salem GJ, et al. Cardiovascular fitness and the metabolic syndrome in overweight latino youths. Med Sci Sports Exerc. 2005;37(6):922-8.

53. Ekelund U, Brage S, Franks PW, Hennings S, Emms S, Wareham NJ. Physical activity energy expenditure predicts progression toward the metabolic syndrome independently of aerobic fitness in middle-aged healthy Caucasians: the Medical Research Council Ely study. Diabetes Care. 2005: 28(5):1195-200. https://doi.org/10.2337/diacare.28.5.1195.

54. Ekelund U, Anderssen SA, Froberg K, Sardinha LB, Andersen LB, Brage S. Independent associations of physical activity and cardiorespiratory fitness with metabolic risk factors in children: the European youth heart study. Diabetologia. 2007;50(9):1832-40. https://doi.org/10.1007/s00125-007-0762-5.

55. Imperatore G, Cheng YJ, Williams DE, Fulton J, Gregg EW. Physical activity, cardiovascular fitness, and insulin sensitivity among U.S. adolescents: the National Health and nutrition examination survey, 1999-2002. Diabetes Care. 2006:29(7):1567-72. https://doi.org/10.2337/dc06-0426.

56. Ball GD, Shaibi GQ, Cruz ML, Watkins MP, Weigensberg MJ, Goran MI. Insulin sensitivity, cardiorespiratory fitness, and physical activity in overweight Hispanic youth. Obes Res. 2004;12(1):77-85. https://doi.org/10.1038/oby.2004.11.

57. Wedell-Neergaard AS, Krogh-Madsen R, Petersen GL, Hansen ÅM, Pedersen BK, Lund R, et al. Cardiorespiratory fitness and the metabolic syndrome: roles of inflammation and abdominal obesity. PLoS One. 2018;13(3): e0194991. https://doi.org/10.1371/journal.pone.0194991.

58. Wei M, Gibbons LW, Mitchell TL, Kampert JB, Lee CD, Blair SN. The association between cardiorespiratory fitness and impaired fasting glucose and type 2 diabetes mellitus in men. Ann Intern Med. 1999;130(2):89-96. https://doi.org/10.7326/0003-4819-130-2-199901190-00002.

59. Stefanick M, Wood P, editors. Physical activity, lipid and lipoprotein metabolism, and lipid transport. Physical activity, fitness and health: International proceedings and consensus statement. Champaign: Human Kinetics; 1994

60. Bouchard C, Rankinen T. Individual differences in response to regular physical activity. Med Sci Sports Exerc. 2001;33(6 Suppl):S446-51; discussion S52-3. https://doi.org/10.1097/00005768-200106001-00013. 
61. Katzmarzyk PT, Church TS, Janssen I, Ross R, Blair SN. Metabolic syndrome, obesity, and mortality: impact of cardiorespiratory fitness. Diabetes Care. 2005;28(2):391-7. https://doi.org/10.2337/diacare.28.2.391.

62. Kouki R, Schwab U, Lakka TA, Hassinen M, Savonen K, Komulainen P, et al. Diet, fitness and metabolic syndrome--the DR's EXTRA study. Nutr Metab Cardiovasc Dis. 2012;22(7):553-60. https://doi.org/10.1016/.jnumecd.2010.10.008.

63. Moreira C, Santos R, Moreira P, Lobelo F, Ruiz JR, Vale S, et al. Cardiorespiratory fitness is negatively associated with metabolic risk factors independently of the adherence to a healthy dietary pattern. Nutr Metab Cardiovasc Dis. 2013;23(7): 670-6. https://doi.org/10.1016/j.numecd.2012.01.011.

64. Liao W, Xiao DM, Huang Y, Yu HJ, Yuan S, Chen T, et al. Combined Association of Diet and Cardiorespiratory Fitness with metabolic syndrome in Chinese schoolchildren. Matern Child Health J. 2016;20(9):1904-10. https://doi.org/10.1007/s10995-016-2001-5.

65. Boreham CA, Ferreira I, Twisk JW, Gallagher AM, Savage MJ, Murray LJ. Cardiorespiratory fitness, physical activity, and arterial stiffness: the Northern Ireland young hearts project. Hypertension. 2004;44(5):721-6. https://doi. org/10.1161/01.HYP.0000144293.40699.9a.

66. Barlow CE, LaMonte MJ, Fitzgerald SJ, Kampert JB, Perrin JL, Blair SN. Cardiorespiratory fitness is an independent predictor of hypertension incidence among initially normotensive healthy women. Am J Epidemiol. 2006;163(2):142-50. https://doi.org/10.1093/aje/kwj019.

67. Lin CY, Chen PC, Kuo HK, Lin LY, Lin JW, Hwang JJ. Effects of obesity, physical activity, and cardiorespiratory fitness on blood pressure, inflammation, and insulin resistance in the National Health and nutrition survey 1999-2002. Nutr Metab Cardiovasc Dis. 2010;20(10):713-9. https://doi. org/10.1016/j.numecd.2009.06.005.

68. Mustelin L, Silventoinen K, Pietiläinen K, Rissanen A, Kaprio J. Physical activity reduces the influence of genetic effects on $\mathrm{BMI}$ and waist circumference: a study in young adult twins. Int J Obes. 2009;33(1):29-36. https://doi.org/10.1038/ijo.2008.258.

69. Parto $P$, Lavie CJ, Swift D, Sui X. The role of cardiorespiratory fitness on plasma lipid levels. Expert Rev Cardiovasc Ther. 2015;13(11):1177-83. https:// doi.org/10.1586/14779072.2015.1092384

70. Drake I, Sonestedt E, Ericson U, Wallström P, Orho-Melander M. A Western dietary pattern is prospectively associated with cardio-metabolic traits and incidence of the metabolic syndrome. Br J Nutr. 2018;119(10):1168-76. https://doi.org/10.1017/s000711451800079x.

71. Peñalvo JL, Oliva B, Sotos-Prieto M, Uzhova I, Moreno-Franco B, León-Latre $M$, et al. Greater adherence to a Mediterranean dietary pattern is associated with improved plasma lipid profile: the Aragon health workers study cohort. Rev Esp Cardiol (Engl Ed). 2015;68(4):290-7. https://doi.org/10.1016/j.rec.2 014.09.019.

\section{Publisher's Note}

Springer Nature remains neutral with regard to jurisdictional claims in published maps and institutional affiliations.

Ready to submit your research? Choose BMC and benefit from:

- fast, convenient online submission

- thorough peer review by experienced researchers in your field

- rapid publication on acceptance

- support for research data, including large and complex data types

- gold Open Access which fosters wider collaboration and increased citations

- maximum visibility for your research: over $100 \mathrm{M}$ website views per year

At $\mathrm{BMC}$, research is always in progress.

Learn more biomedcentral.com/submissions 